\title{
A Suggested Approach to Overcoming Obstacles of Learning Chemistry for Ninth Grader Students in The Syrian Arab Republic-Idlib Suburb Refugee Camps as Perceived by Teachers and Students
}

\author{
Anber M. Anber ${ }^{1} \&$ Safia Naji Al-Duais ${ }^{1}$ \\ ${ }^{1}$ Curriculum and Instruction, Al-Madinah International University (MEDIU), Malaysia \\ Correspondence: Anber M. Anber, Curriculum and Instruction, Al-Madinah International University (MEDIU), \\ Malaysia.
}

Received: May 5, 2019

Accepted: August 25, 2019

Online Published: November 29, 2019

doi:10.5539/ies.v12n12p13

URL: https://doi.org/10.5539/ies.v12n12p13

\begin{abstract}
This study aims to identify the obstacles of learning chemistry for ninth grade students in Syrian Arab Republic-Idlib Suburb Refugee camps and suggest solutions to overcome these obstacles. The study followed an analytical descriptive approach using two questionnaires of (58) items of questions for teachers and (18) for students. The population of the study included (27) teachers of chemistry and (91) ninth grade in schools in students in Idlib Refugee camps between 2016 and 2018. The SPSS program adopted for the analysis of data and the statistical study showed the following results: the obstacles identified by teachers included tools, materials, and structures of laboratories as the most significant, as well as the situation of schools and the education environment in the camps. Students also identified obstacles related to tools, materials, and the structure of laboratories, then difficulties with teachers, availability and content of chemistry textbooks, and finally personal or interpersonal difficulties. The results showed there are no statistically significant differences at the level $(0.05)$ between the estimates of chemistry teachers or students regarding obstacles related to gender. Similarly there were no statistically significant differences at the level $(0.05)$ between the estimates of chemistry teachers regarding the variable number of years of experience or degree of university qualification or variable number of schools in which teachers teach, and statistically significant difference at the level $(0.01)$ due to variable number of schools in which teachers teach.
\end{abstract}

Keywords: obstacles, chemistry learning, ninth grade students, refugee camps, Idlib, Syria

\section{Introduction}

Chemistry is one of the basic sciences that students begin separately study at intermediate stage in Syrian formal education, they study necessary chemical information and the most important discoverers that will need in life, and therefore it is an important factor to change the mental structure of students. Chemistry provides a basic knowledge of useful methods for students that help to solve many life problems and improves ability to understand and explain chemical phenomena, but many obstacles of learning chemistry weaken their ability to earn effectively, (Al-Saady \& Ouda, 2006; Zayton, 2008; Al-Dofairy \& Habib, 2012; At-Allah, 2001; Taha, 2008). Students find chemistry the most difficult subject to understand (Hindi, 2008). Many studies for more than three decades showed traditional methods of general science teaching aren't highly effective in chemistry teaching because of focusing on memorizing information without understanding and assimilation, in addition the students have a negative attitude in class; this is partly because of old-fashioned teacher-centered teaching where students are expected only to listen (Al-Rasheed, 2003). Despite all efforts from teachers and educations supervisors reluctant to engage with chemistry such as low ability of teacher's to work in a laboratories and practical parts (Jegde, 2007). The great development of chemistry pushes many new teaching methods to develop and students work together in classes and motivate them to understand and develop the ability of understand and solve problems, so many studies support practical chemistry curriculums and laboratories (Mahmoud, 2012). Research suggests a new scheme for science that is strongly linked to a laboratory as a way to concepts, facts, laws and theories science knowing (Abo-Jlala, 2005). Applied scientific materials teaching especially chemistry have many problems such as lack of teacher practical skills in the laboratory, lack of students activity in classes, lack of tools and devices, excess 
students numbers, lack of necessary safe requirements for experiments and lack of training courses for teachers in new chemistry curriculums (Al-Hammadi, 2007; Al-Rifai, 2006). Also a lack of a laboratory room, lack of a laboratory assistant, large curriculum and the examinations from education ministry taking theoretical sides of curriculum are obstacles (Mahmoud, 2010). The students have better learning when they use experimenting in the laboratory to solve problems, (Admas, \& Adane, 2011). Obstacles of chemistry were because of a lack of necessary tools and materials for both teachers and students needed to conduct experiments, and a short time to activate and experiment with new knowledge and the chemistry curriculum teachers have to use is large, (Al-Suwian, 2006). The most important obstacles of practical applications are the non-suitability of the chemistry curriculum with weekly classes' numbers, a lack of practical applications and a lack of laboratory training stages for teachers in the university (Taha, 2008). About $90 \%$ of chemistry teachers attributed obstacles to their requirements for laboratory working time, and about $86 \%$ to lack of equipment, materials and tools in laboratories, and about $80 \%$ to lack of students who are interested in learning chemistry and the packed classes that impedes both chemistry teaching and successful use of laboratories (BouJaoude, 2006). The study about chemistry teachers in Izmir in Turkey showed large range of scientific methods using, activities and experiments because materials and devices was provided in laboratories, also the teachers have a lot of experience and are over (26) years old (Feyzioglu et al., 2011). Through discussions with chemistry teachers and students of ninth grader students in refugee camps we can see they have many obstacles of chemistry learning, including obstacles of chemistry curriculum, students, teachers, schools, classroom environment and laboratories. This study intends to highlight the most important obstacles and which have the greatest effect on chemistry learning with a suggested approach to overcoming these obstacles of ninth grade students in Idlib refugee camps.

\section{Purpose of the Study and Research Questions}

The purpose of this study was to identify the obstacles of learning chemistry for ninth grader students in Syrian Arab republic-Idlib suburb refugee camps as perceived by teachers and students and to suggest approach to overcoming these obstacles.

\subsection{The Main Question}

What is the suggested approach to overcoming the obstacles of learning chemistry for ninth grader students in Syrian Arab republic-Idlib suburb refugee camps as perceived by teachers and students?

\subsection{The Sub-Questions}

1) What are the obstacles of learning chemistry for ninth grader students as perceived by teachers?

2) What are the obstacles of learning chemistry for ninth grader students as perceived by students?

3) Are there any differences between the estimates of chemistry teachers regarding the obstacles of learning chemistry for ninth grader students due to gender?

4) Are there any differences between the estimates of students regarding the obstacles of learning chemistry for ninth grader students due to gender?

5) Are there any differences between the estimates of chemistry teachers regarding the obstacles of learning chemistry for ninth grader students due to (variable number of years of experience-degree of university qualification-variable numbers of schools in which teachers teach)?

6) What is the suggested approach to overcoming obstacles of learning chemistry for ninth grader students in the Syrian Arab Republic-Idlib suburb refugee camps as perceived by teachers and students?

\section{Methodology}

\subsection{Population of the Study}

The population for the research consists of chemistry teachers and ninth grade students in schools of Idlib refugee camps associated with educational association of the displaced. The estimated numbers are about (35) chemistry teachers and (1400) ninth grade students advanced of them to final exam (728) students consisting of (359) males and (369) females and the students who have done the final exam (650) according to the statistics of educational directorate in Idlib. The percentage of ninth grade students in schools of Idlib refugee camps are estimated at about $(10 \%)$ of all ninth grade students in schools of Idlib governorate which is estimated at about (14100) ninth grade students. All data collection is between 2016 and 2018.

\subsection{Sample Size}

The sample was random selected of (27) chemistry teachers in schools of Idlib refugee camps consist of (23) male and (4) female. A simple random sample was used to select (91) ninth grade students in schools of Idlib refugee 
camps which are estimated to be about (10\%) of all ninth grade students in schools of Idlib refugee camps and to consist of (45) males and (46) females, according to data analysis in 2018, all simples was randomly selected.

\subsection{Validity and Reliability}

The two questionnaires were checked by nine professors and teachers in Al-Madinah International University, Idlib University and Sham University and notes were taken and corrections were made to items on the questionnaires.

\subsubsection{Reliability by Split Half Coefficient}

The correlation coefficient was calculated between questions that have odd numbers and those that have even numbers in each dimension of the teacher's questionnaire and the student's questionnaire, and corrected with correlation coefficients by Guttman-Split Half Coefficient because of difference in Cronbach's Alpha Coefficient and variance differences between two parts of odd numbers and even numbers as in Table 1.

Table 1. Questionnaires reliability by Guttman-Split Half Coefficient

\begin{tabular}{llcc}
\hline \multirow{2}{*}{ Obstacles } & \multicolumn{2}{c}{ Split Half Coefficient } \\
\cline { 2 - 4 } 1 & Obstacles related to chemistry textbooks. & Teachers & Students \\
\hline 2 & Obstacles related to students. & 0.647 & 0.388 \\
3 & Obstacles related to teachers. & 0.894 & 0.609 \\
4 & Obstacles related to schools and education environment. & 0.948 & 0.487 \\
5 & Obstacles related to tools, materials, and structures of laboratories. & 0.854 & -1.135 \\
All fields & 0.546 & 1.000 \\
\hline
\end{tabular}

The Table 1 shows the Guttman-Split Half Coefficient between the teachers' questionnaire items and the total Guttman-Split Half Coefficient which have high values and were reassured to applicant on a study sample. The Guttman-Split Half Coefficient s between items of students' questionnaire showed values of Guttman-Split Half Coefficient s were medium to first and third dimensions and high for second and fifth dimensions. The fourth dimension of students' questionnaire which showed a negative value was explained by the fact that the students didn't have a clear idea about obstacles related to schools and education environment and gave different answers; therefore, this dimension was deleted from the student questionnaire.

\subsubsection{Reliability by Cronbach's Alpha Coefficient}

Cronbach's Alpha Coefficient was used to confirm whether the teachers' questionnaire and students' questionnaire were stable to test chemistry learning obstacles as in Table 2.

Table 2. Questionnaires reliability by Cronbach's Alpha

\begin{tabular}{llcc}
\hline \multirow{2}{*}{ Obstacles } & \multicolumn{2}{c}{ Cronbach's Alpha } \\
\cline { 3 - 4 } & Teachers & Students \\
\hline 1 & Obstacles related to chemistry textbooks. & 0.513 & 0.365 \\
2 & Obstacles related to students. & 0.888 & 0.357 \\
3 & Obstacles related to teachers. & 0.848 & 0.504 \\
4 & Obstacles related to schools and education environment. & 0.854 & -0.422 \\
5 & Obstacles related to tools, materials, and structures of laboratories. & 0.524 & 1.000 \\
All fields & 0.707 & 0.539 \\
\hline
\end{tabular}

The Table 2 shows the reliability coefficients calculated by Cronbach's Alpha method for teacher questionnaire items and total reliability coefficients which have high values and were reassured to apply on the teachers sample. The reliability coefficients between student questionnaire items showed values of stability coefficients ranging from medium to first and second dimensions and high to third dimension and very high to fifth dimension. The fourth dimension which showed a negative value of reliability coefficient and that confirmed results of Guttman-Split Half Coefficient. The total Cronbach's Alpha reliability coefficient to students' questionnaire is high and reassured to apply on the students' sample. 


\section{Results}

\subsection{The Obstacles of Learning Chemistry for Ninth Grader Students as Perceived by Teachers}

The questionnaire was divided into five main dimensions of the study of obstacles. The statistical Coefficient of variables as averages, standard deviations and relative weights of each item were calculated.

Table 3. Obstacles related to chemistry textbooks as perceived by teachers.

\begin{tabular}{|c|c|c|c|c|c|c|}
\hline & Items & Mean & $\begin{array}{c}\text { Std. } \\
\text { Deviation } \\
\end{array}$ & $\begin{array}{r}\text { Relative } \\
\text { Weight }\end{array}$ & Level & Rank \\
\hline 1 & Lack of chemical ideas using at textbook in live of students. & 3.222 & 1.086 & 64.44 & Medium & 1 \\
\hline 2 & $\begin{array}{l}\text { Weak serial correlation between textbook units with regard to chemical } \\
\text { concepts. }\end{array}$ & 2.852 & 1.027 & 57.04 & Medium & 4 \\
\hline 3 & The difficulty of chemical concepts in new curriculum. & 2.519 & 0.975 & 50.37 & Low & 8 \\
\hline 4 & Lack of consideration of individual difference in exercises or activates. & 3.074 & 0.997 & 61.48 & Medium & 3 \\
\hline 5 & $\begin{array}{l}\text { Weak technical construction of the book (Cover, Graphics, Figures, } \\
\text { Printing, ... etc.) }\end{array}$ & 2.111 & 1.013 & 42.22 & Low & 9 \\
\hline 6 & Lack consideration of innovation in the text book. & 3.111 & 0.892 & 62.22 & Medium & 2 \\
\hline 7 & Scientific experiments need a long time to conduct them. & 3.222 & 1.086 & 64.44 & Medium & 1 \\
\hline 8 & A lot of padding in the book. & 2.815 & 1.241 & 56.30 & Medium & 5 \\
\hline 9 & $\begin{array}{l}\text { Some chapters in book depend on topics from previous grades not } \\
\text { focused. }\end{array}$ & 2.741 & 1.196 & 54.81 & Medium & 6 \\
\hline \multirow[t]{2}{*}{10} & Lack of objectives and experiences clarity of lessons. & 2.630 & 1.182 & 52.59 & Medium & 7 \\
\hline & All Items & 2.830 & 1.108 & 56.59 & Medium & \\
\hline
\end{tabular}

Table 3 shows the values of the arithmetic averages and the relative weights of obstacles related to chemistry learning of textbooks as perceived by teachers, the arithmetic average of all items was (2.830) with medium degree and relative weight of (56.59\%), the arithmetic averages in the dimension ranging between (3.22) and (2.11). Item (1) and item (7) obtained together a highest arithmetic average with relative weights of (64.44\%) and a medium level of both items in the first dimension, followed by item (6) with relative weight of (62.22\%) a medium level. Item (4) obtained a relative weight of (61.48\%) and medium level. Item (3) came second to last with relative weight of (50.37\%) and low level. In last place was item (5) with relative weight of (42.22\%) and low level.

Table 4. Obstacles related to students as perceived by teachers

\begin{tabular}{|c|c|c|c|c|c|c|}
\hline & Items & Mean & $\begin{array}{c}\text { Std. } \\
\text { Deviation }\end{array}$ & $\begin{array}{l}\text { Relative } \\
\text { Weight }\end{array}$ & level & Rank \\
\hline 1 & Lack of student's interest in homework. & 3.630 & 0.967 & 72.59 & Large & 6 \\
\hline 2 & Lack of student's interest in chemistry collection. & 3.444 & 1.050 & 68.89 & Large & 8 \\
\hline 3 & Lack of an environment that is conducive to studying at home. & 3.741 & 1.375 & 74.81 & Large & 5 \\
\hline 4 & Lack of questions about the unclear points in the class. & 3.333 & 1.074 & 66.67 & Medium & 9 \\
\hline 5 & Difficult security and economic conditions surrounding students. & 4.111 & 1.219 & 82.22 & Large & 3 \\
\hline 6 & Lack of follow-up of families to their children's test results. & 4.074 & 0.917 & 81.48 & Large & 4 \\
\hline 7 & Weak general level of students in chemistry & 3.630 & 0.926 & 72.59 & Large & 6 \\
\hline 8 & Students feel that practical applications have little link to their lives. & 3.630 & 0.967 & 72.59 & Large & 6 \\
\hline 9 & Lack of student's interest in practical experiences. & 3.593 & 1.185 & 71.85 & Large & 7 \\
\hline 10 & $\begin{array}{l}\text { Lack of student's observance of safety and security precautions during } \\
\text { experiments. }\end{array}$ & 3.222 & 1.251 & 64.44 & Medium & 10 \\
\hline 11 & Students return to memorization without understanding. & 4.370 & 0.839 & 87.41 & V. & 1 \\
\hline 12 & Students are out of school for a long time. & 4.296 & 0.953 & 85.93 & V. & 2 \\
\hline \multirow[t]{2}{*}{13} & The difference between students' ages. & 3.111 & 1.188 & 62.22 & Medium & 11 \\
\hline & All Items & 3.707 & 1.130 & 74.13 & Large & \\
\hline
\end{tabular}

Table 4 shows the values of the arithmetic averages and the relative weights of obstacles of chemistry learning related to students as perceived by teachers, the arithmetic average of all items was (3.70) and relative weight of (74.13\%), the arithmetic averages in the dimension ranging between (4.37) and (3.11). Item (11) obtained the 
highest arithmetic average of the obstacles in the second dimension with relative weight of $(87.41 \%)$ and very large level, followed by item (12) with relative weight of $(85.93 \%)$ and very large level, then item (5) with a relative weight of $(82.22 \%)$ and large level. Item (10) came second to last with a relative weight of $(64.44 \%)$ and medium level. In last place was item (13) with relative weight of (62.22\%) and medium level.

Table 5. Obstacles related to teachers as perceived by teachers

\begin{tabular}{|c|c|c|c|c|c|c|}
\hline & Items & Mean & $\begin{array}{c}\text { Std. } \\
\text { Deviation }\end{array}$ & $\begin{array}{l}\text { Relative } \\
\text { Weight }\end{array}$ & Level & Rank \\
\hline 1 & Lack of teacher use of various teaching methods. & 3.630 & 0.884 & 72.59 & Large & 5 \\
\hline 2 & Lack of teacher use of reinforcement methods. & 3.370 & 0.926 & 67.41 & Medium & 8 \\
\hline 3 & $\begin{array}{l}\text { Lack of diversity of evaluation methods which is followed by the teacher } \\
\text { to measure learning outcomes. }\end{array}$ & 3.148 & 0.907 & 62.96 & Medium & 11 \\
\hline 4 & Lack of teacher use of educations tools. & 3.778 & 0.974 & 75.56 & Large & 3 \\
\hline 5 & Lack of clarification of classes' objective as well before starting it. & 2.889 & 0.974 & 57.78 & Medium & 12 \\
\hline 6 & Lack of plans prepared for students there have low collection. & 3.704 & 1.203 & 74.07 & Large & 4 \\
\hline 7 & Heavy workload for teachers. & 3.222 & 1.155 & 64.44 & Medium & 9 \\
\hline 8 & $\begin{array}{l}\text { Teacher believes that some minor chemical topics do not need to make } \\
\text { practical experiments. }\end{array}$ & 3.407 & 1.083 & 68.15 & Large & 7 \\
\hline 9 & Lock of motivation for teacher to make experiments. & 4.037 & 0.854 & 80.74 & Large & 2 \\
\hline 10 & Lack of time to prepare and make experiments. & 4.370 & 0.926 & 87.41 & $\begin{array}{c}\text { V. } \\
\text { Large }\end{array}$ & 1 \\
\hline 11 & Lack of knowledge for some teachers of the experiments skills. & 3.370 & 1.006 & 67.41 & Medium & 8 \\
\hline 12 & Teachers' lack of confidence in working in laboratory. & 3.222 & 1.155 & 64.44 & Medium & 9 \\
\hline 13 & Lack of training courses for teachers of new chemistry curriculum. & 3.704 & 1.265 & 74.07 & Large & 4 \\
\hline 14 & Lack of numbers of teachers specializing in chemistry. & 3.704 & 1.436 & 74.07 & Large & 4 \\
\hline 15 & Low scientific level of teachers. & 3.185 & 1.210 & 63.70 & Medium & 10 \\
\hline \multirow[t]{2}{*}{16} & Lack of follow up of teacher to new developments in chemistry & 3.444 & 1.013 & 68.89 & Large & 6 \\
\hline & All Items & 3.512 & 1.113 & 70.23 & Large & \\
\hline
\end{tabular}

Table 5 shows the values of the arithmetic averages and the relative weights of obstacles of chemistry learning related to teachers as perceived by teachers, the arithmetic average of all items was (3.512) and relative weight of $(70.23 \%)$, the arithmetic averages in the dimension ranging between (4.370) and (2.889). Item (10) obtained the highest arithmetic average of obstacles in the third dimension with relative weight of $(87.41 \%)$ and very large level, followed by item (9) with relative weight of (80.74\%) and large level, then item (4) with relative weight of (75.56\%) and large level. Item (3) came second to last with a relative weight of $(62.96 \%)$ and medium level. In last place was item (5) with relative weight of (57.78\%) and medium level.

Table 6. Obstacles related to schools and education environment as perceived by teachers

\begin{tabular}{|c|c|c|c|c|c|c|}
\hline & Items & Mean & Std. Deviation & Relative Weight & level & Rank \\
\hline 1 & Lack of a suitable learning environment in the school. & 3.519 & 1.014 & 70.37 & Large & 3 \\
\hline 2 & Increase of students numbers in class. & 3.222 & 1.155 & 64.44 & Medium & 4 \\
\hline 3 & The school place is far from the students houses. & 3.148 & 1.064 & 62.96 & Medium & 5 \\
\hline 4 & Lack of weekly classes of chemistry. & 3.148 & 1.027 & 62.96 & Medium & 5 \\
\hline 5 & Lack of communication between school and student family. & 3.741 & 0.859 & 74.81 & Large & 1 \\
\hline 6 & Lack of relevant timeliness of chemistry classes. & 2.815 & 0.736 & 56.30 & Medium & 6 \\
\hline 7 & Lack of availability of chemical references in the school library. & 3.222 & 1.368 & 64.44 & Medium & 4 \\
\hline \multirow[t]{2}{*}{8} & Automatic upgrade of students. & 3.593 & 1.248 & 71.85 & Large & 2 \\
\hline & All Items & 3.301 & 1.094 & 66.02 & Medium & \\
\hline
\end{tabular}

Table 6 shows the values of the arithmetic averages and the relative weights of obstacles of chemistry learning related to schools and education environment as perceived by teachers, the arithmetic average of all items was (3.301) with relative weight of (66.02\%), the arithmetic averages in the dimension ranging between (3.741) and (2.815). Item (5) obtained the highest arithmetic average of obstacles in the fourth dimension with relative weight 
of (74.81\%) and large level, followed by item (8) with relative weight of (71.85\%) and large level, then item (1) with relative weight of (70.37\%) and large level. Item (3) and item (4) came second to last with a relative weight of $(62.96 \%)$ and medium levels of both items. Finally, item (6) was with relative weight of (56.30\%) and medium level.

Table 7. Obstacles related to tools, materials, and structures of laboratories as perceived by teachers

\begin{tabular}{|c|c|c|c|c|c|c|}
\hline & Items & Mean & $\begin{array}{c}\text { Std. } \\
\text { Deviation }\end{array}$ & $\begin{array}{l}\text { Relative } \\
\text { Weight }\end{array}$ & level & Rank \\
\hline 1 & Lack of availability laboratories in schools. & 4.630 & 0.688 & 92.59 & $\begin{array}{c}\text { V. } \\
\text { Large }\end{array}$ & 1 \\
\hline 2 & Lack of necessary extensions in the laboratory (water, electricity, heat). & 4.481 & 0.849 & 89.63 & $\begin{array}{c}\text { V. } \\
\text { Large }\end{array}$ & 3 \\
\hline 3 & Small laboratory area. & 4.037 & 1.018 & 80.74 & Large & 8 \\
\hline 4 & Lack of experimental preparation room separate from the laboratory. & 4.370 & 0.839 & 87.41 & $\begin{array}{c}\text { V. } \\
\text { Large }\end{array}$ & 4 \\
\hline 5 & $\begin{array}{l}\text { Lack of security and safety in the laboratory (fire extinguishers, fire } \\
\text { detector, first aids). }\end{array}$ & 4.259 & 1.196 & 85.19 & $\begin{array}{c}\text { V. } \\
\text { Large }\end{array}$ & 6 \\
\hline 6 & Lack of good and continuous airing of the laboratory. & 4.185 & 0.921 & 83.70 & Large & 7 \\
\hline 7 & Lack of devices and tools for experiments. & 4.593 & 0.747 & 91.85 & $\begin{array}{c}\text { V. } \\
\text { Large }\end{array}$ & 2 \\
\hline 8 & Weak of financial for laboratory experiments. & 4.333 & 0.920 & 86.67 & $\begin{array}{c}\text { V. } \\
\text { Large }\end{array}$ & 5 \\
\hline 9 & Lack of maintenance of laboratory hardware and tools as well. & 4.037 & 1.126 & 80.74 & Large & 8 \\
\hline 10 & $\begin{array}{l}\text { Lack of interest in organizing devices and tools, and returning them to } \\
\text { their places. }\end{array}$ & 3.815 & 1.001 & 76.30 & Large & 10 \\
\hline 11 & Expiry of some chemicals. & 3.963 & 0.898 & 79.26 & Large & 9 \\
\hline & All Items & 4.246 & 0.957 & 84.92 & $\begin{array}{c}\text { V. } \\
\text { Large }\end{array}$ & \\
\hline
\end{tabular}

Table 7 shows the values of the arithmetic averages and the relative weights of obstacles of chemistry learning related to tools, materials, and structures of laboratories as perceived by teachers, the arithmetic average of all items was (4.246) with relative weight of (84.92\%), the arithmetic averages in the dimension ranging between (4.630) and (3.815). Item (1) obtained the highest arithmetic average of obstacles in the fifth dimension with relative weight of $(92.59 \%)$ and very high level, followed by item (7) with relative weight of $(91.85 \%)$ and very high level, then item (2) with relative weight of (89.63\%) and very high level. Item (11) came second to last with a relative weight of (79.26\%) and large level. In last place was item (10) with relative weight (76.30\%) and large level.

Table 8. Comparison between five dimensions of obstacles as perceived by teachers

\begin{tabular}{|c|c|c|c|c|c|c|}
\hline & Dimensions of Obstacles & Mean & Std. Deviation & Relative Weight & level & Rank \\
\hline 1 & Obstacles related to chemistry textbooks. & 2.830 & 1.108 & 56.59 & Medium & 5 \\
\hline 2 & Obstacles related to students. & 3.707 & 1.130 & 74.13 & Large & 2 \\
\hline 3 & Obstacles related to teachers. & 3.512 & 1.113 & 70.23 & Large & 3 \\
\hline 4 & Obstacles related to schools and education environment. & 3.301 & 1.094 & 66.02 & Medium & 4 \\
\hline \multirow[t]{2}{*}{5} & Obstacles related to tools, materials, and structures of laboratories. & 4.246 & 0.957 & 84.92 & V. Large & 1 \\
\hline & All dimensions & 3.519 & 1.171 & 70.38 & Large & \\
\hline
\end{tabular}

Table 8 shows the values of the arithmetic averages and the relative weights of obstacles of chemistry learning between five dimensions of total questionnaire as perceived by teachers, the arithmetic average of all dimensions was (3.519) with relative weight of $(70.38 \%)$, the arithmetic averages of questionnaire dimensions ranging between (4.246) and (2.830). The dimension (5) obtained the highest arithmetic average of obstacles in the questionnaire between dimensions with relative weight of (84.92\%) and very large level, followed by dimension (2) with relative weight of (74.13\%) and large level, then dimension (3) with relative weight of (70.23\%) and large 
level. The dimension (4) came second to last with a relative weight of (66.02\%) and medium level, and finally, dimension (1) with relative weight (56.59\%) and medium level.

The study agreed with the results of many studies (Taha, 2008; Al-Hammadi, 2007; Al-Rifai, 2006; Al-Suwian, 2006; BouJaoude, 2006; Al-Khalili, 1988), that there was a lack of equipment, tools, materials, safety requirements necessary and structures of laboratories.

The study differed from (Basul, 1987) study in most effective obstacles of learning chemistry as perceived by teachers were related to students with highest average then related to teachers, then related to laboratory and lack of teachers academic training, finally the obstacles of administrative organization. The study differed from Al-Hartomy's (2014) study in that obstacles that had the highest average were related to textbook and school programs, followed by obstacles related to equipment and materials, followed by obstacles related to students, then obstacles related to chemistry teachers and laboratory assistants, finally the obstacles related to laboratory room and laboratory requirements. It also differed from (Feyzioglu et al., 2011) study that founded that chemistry teachers frequently used scientific methods, activities and experiments based on theories because they could afford materials and devices in chemistry laboratory. The agreement and the difference with study results because of a lack of laboratory application of experiments and this was reflected in a large range in students' level. However, when laboratory was effective in classes that often led to improvement in a student's level and at the same time showed the obstacles related to curriculum and related to teachers and students carrying out experiments and laboratory activities.

\subsection{The Obstacles of Learning Chemistry for Ninth Grader Students as Perceived by Students}

The questionnaire was divided into four main dimensions of the study of obstacles. The statistical factors of variables as averages, standard deviations and relative weights of each item were calculated.

Table 9. Obstacles related to chemistry textbooks as perceived by students

\begin{tabular}{llccccc}
\hline & Items & Mean & Std. Deviation & Relative Weight & level & Rank \\
\hline 1 & Difficult chemistry classes. & 1.908 & 0.615 & 63.60 & Medium & 3 \\
2 & Exercises at the end of the classes are long. & 1.842 & 0.674 & 61.40 & Medium & 2 \\
3 & Activities and experiences in the book are long. & 2.013 & 0.757 & 67.11 & Medium & 4 \\
4 & The chemistry books are available in school. & 1.750 & 0.866 & 58.33 & Medium & 1 \\
& All Items & 1.878 & 0.737 & 62.61 & Medium \\
\hline
\end{tabular}

Table 9 shows the values of the arithmetic averages and the relative weights of obstacles related to chemistry learning of textbooks as perceived by students, the arithmetic average of all items was (1.878) with medium degree and relative weight of (62.61\%), the arithmetic averages in the dimension ranged between (2.013) and (1.750). Item (3) obtained the highest arithmetic average in the first dimension with relative weight of $(67.11 \%)$ and medium level, followed by item (1) with relative weight of (63.60\%) and medium level, then item (2) came second to last with a relative weight of (61.40\%) and medium level. In last place was item (4) with relative weight of $(58.33 \%)$ and medium level.

Table 10. Obstacles related to students as perceived by students

\begin{tabular}{llccccc}
\hline & Items & Mean & Std. Deviation & Relative Weight & level & Rank \\
\hline 1 & Homework writing. & 2.013 & 0.739 & 67.11 & Medium & 3 \\
2 & Interest of chemistry. & 2.132 & 0.699 & 71.05 & Medium & 4 \\
3 & Availability of study environment at home. & 1.829 & 0.700 & 60.96 & Medium & 1 \\
4 & Difficulty of security and living conditions. & 1.921 & 0.762 & 64.04 & Medium & 2 \\
5 & The students are afraid of doing chemical experiments. & 2.382 & 0.783 & 79.39 & Large & 5 \\
& All Items & 2.055 & 0.758 & 68.51 & Medium & \\
\hline
\end{tabular}

Table 10 shows the values of the arithmetic averages and the relative weights of obstacles related to students as perceived by students, the arithmetic average of all items was (2.055) with medium degree and relative weight of (68.51\%), the arithmetic averages in the dimension ranged between (2.382) and (1.829). Item (5) obtained the highest arithmetic average in the second dimension with relative weight of (79.39\%) and large level, followed by item (2) with relative weight of (64.04\%) and medium level, then item (4) with relative weight of $(67.11 \%)$ and 
medium level. Item (5) came second to last with a relative weight of (64.04\%) and medium level. In last place was item (3) with relative weight of $(60.96 \%)$ and medium level.

Table 11. Obstacles related to teachers as perceived by students

\begin{tabular}{llccccc}
\hline & Items & Mean & Std. Deviation & Relative Weight & level & Rank \\
\hline 1 & Explanation of information by the teacher. & 1.658 & 0.809 & 55.26 & Low & 2 \\
2 & Taking classes in the laboratory. & 1.289 & 0.585 & 42.98 & Low & 1 \\
3 & Using the education tools in the classes. & 1.934 & 0.822 & 64.47 & Medium & 5 \\
4 & The teacher repeating the explanation of information. & 1.697 & 0.766 & 56.58 & Medium & 3 \\
5 & Using the chemical symbols by teacher. & 1.816 & 0.844 & 60.53 & Medium & 4 \\
& All Items & 1.679 & 0.797 & 55.96 & Medium & \\
\hline
\end{tabular}

Table 11 shows the values of the arithmetic averages and the relative weights of obstacles related to teachers as perceived by students, the arithmetic average of all items was (1.679), with relative weight of (55.96\%), the arithmetic averages in the dimension ranged between (1.934) and (1.289). Item (3) obtained the highest arithmetic average in the third dimension with relative weight of (64.47\%) and medium level, followed by item (5) with relative weight of $(60.53 \%)$ and medium level, then item (4) with relative weight of (56.58\%). Item (1) came second to last with a relative weight of $(55.26 \%)$ and low level. In last place was item (2) with relative weight $(42.98 \%)$ and low level.

Table 12. Obstacles related to tools, materials, and structures of laboratories as perceived by students

\begin{tabular}{llccccc}
\hline & Items & Mean & Std. Deviation & Relative Weight & level & Rank \\
\hline 1 & Availability of a private laboratory room. & 1.092 & 0.291 & 36.40 & Low & 1 \\
2 & Devices and tools for laboratory experiments. & 1.079 & 0.271 & 35.96 & Low & 2 \\
& All Items & 1.086 & 0.281 & 36.18 & Low & \\
\hline
\end{tabular}

Table 12 shows the values of the arithmetic averages and the relative weights of obstacles related to tools, materials, and structures of laboratories as perceived by students, the arithmetic average of all items was (1.086) with relative weight of (36.18\%). Item (1) obtained the highest arithmetic average in the fourth dimension with a relative weight of (36.40\%) and low level, then item (2) with a relative weight of (35.96\%) and low level.

Table 13. Comparison between five dimensions of obstacles as perceived by students as perceived by students

\begin{tabular}{llccccc}
\hline & Dimensions of Obstacles & Mean & Std. Deviation & Relative Weight & level & Rank \\
\hline 1 & Obstacles related to chemistry textbooks. & 1.878 & 0.737 & 62.61 & Medium & 3 \\
2 & Obstacles related to students. & 2.055 & 0.758 & 68.51 & Medium & 4 \\
3 & Obstacles related to teachers. & 1.679 & 0.797 & 55.96 & Medium & 2 \\
4 & Obstacles related to tools, materials, and structures of laboratories. & 1.086 & 0.281 & 36.18 & Low & 1 \\
All dimensions & 1.675 & 0.782 & 62.42 & Medium \\
\hline
\end{tabular}

Table 13 shows the values of the arithmetic averages and the relative weights of obstacles of chemistry learning between four dimensions of total questionnaire as perceived by students, the arithmetic average of all dimensions was (1.675) with relative weight of $(62.42 \%)$, the arithmetic averages of questionnaire dimensions ranged between (2.055) and (1.086). The dimension (2) obtained the highest arithmetic average of obstacles in the questionnaire between dimensions with relative weight of $(68.51 \%)$ and medium level. Followed by dimension (1) with relative weight of (62.61\%) and medium level, then dimension (3) with a relative weight of (55.96\%) and medium level, finally the dimension (4) came in last place with relative weight of (36.18\%) and low level.

The results of this study agreed with Admas and Adane's (2011) study, that students learn better when conducting practical chemical experiments in a laboratory, and that students achieved the objectives of classes better when they conducted experiments to solve scientific problems. Also, teachers faced problems with students regarding safety rules of the laboratory when they conducted scientific experiments. The results of the study agreed with Al-Hammadi's (2007) study, that there was lack of equipment, materials, tools, and necessary safety requirements 
for laboratories.

\subsection{Are There Any Differences Between the Estimates of Chemistry Teachers Regarding the Obstacles of Chemistry Learning for Ninth Grader Students Due to Gender?}

The Mann Whitney (U) test showed a difference between the estimates of chemistry teachers regarding the obstacles of chemistry learning for ninth grader students due to gender, this test was used to indicate the differences between two independent samples which cannot be tested by $(t)$ test because a normality test did not occur and the teacher sample was greater than $(0.05)$ as Table 14 .

Table 14. The difference between the estimates of chemistry teachers regarding obstacles of chemistry learning due to gender

\begin{tabular}{|c|c|c|c|c|c|c|}
\hline Dimensions of Obstacles & gender & number & Mean rank & Sum of rank & $\mathrm{U}$ & Sig. \\
\hline \multirow{2}{*}{ 1) Obstacles related to chemistry textbooks. } & Male & 23 & 14.24 & 327.50 & \multirow{2}{*}{40.500} & \multirow{2}{*}{0.705} \\
\hline & Female & 4 & 12.63 & 50.50 & & \\
\hline \multirow{2}{*}{ 2) Obstacles related to students. } & Male & 23 & 15.04 & 346.00 & \multirow{2}{*}{22.000} & \multirow{2}{*}{0.100} \\
\hline & Female & 4 & 8.00 & 32.00 & & \\
\hline \multirow{2}{*}{ 3) Obstacles related to teachers. } & Male & 23 & 13.50 & 310.50 & \multirow{2}{*}{34.500} & \multirow{2}{*}{0.431} \\
\hline & Female & 4 & 16.88 & 67.50 & & \\
\hline \multirow{2}{*}{ 4) Obstacles related to schools and education environment. } & Male & 23 & 13.74 & 316.00 & \multirow{2}{*}{40.000} & \multirow{2}{*}{0.680} \\
\hline & Female & 4 & 15.50 & 62.00 & & \\
\hline \multirow{2}{*}{ 5) Obstacles related to tools, materials, and structures of laboratories. } & Male & 23 & 12.89 & 296.50 & \multirow{2}{*}{20.500} & \multirow{2}{*}{0.080} \\
\hline & Female & 4 & 20.38 & 81.50 & & \\
\hline \multirow{2}{*}{ All Items } & Male & 23 & 14.04 & 323.00 & \multirow{2}{*}{45.000} & \multirow{2}{*}{0.946} \\
\hline & Female & 4 & 13.75 & 55.00 & & \\
\hline
\end{tabular}

The results in Table 14 indicate apparent differences in averages between the teachers' estimates regarding obstacles of chemistry learning for ninth grader students due to gender. The probability values of the results ranged from (0.080) to $(0.705)$, and for total dimensions was $(0.964)$ which greater than $(0.05)$ and non-statistically significant, which means there are no statistically significant differences between teachers' estimates regarding obstacles of chemistry learning for ninth grader students in refugee camps schools due to differences in teacher gender. The non-statistically significant differences between the responses indicate that teachers of any gender teach the same curriculum, are exposed to the same obstacles and problems, have the same work environments, school equipment, low salaries, and working pressures and also that they are graduates from universities that have a similar curriculum.

\subsection{Are There Any Differences Between the Estimates of Students Regarding the Obstacles of Chemistry Learning for Ninth Grader Students Due to Gender?}

The Independent Samples Test ( $\mathrm{t}$ ) was used indicate to specific differences between the estimates of chemistry students regarding the obstacles of chemistry learning for ninth grader students due to gender. This test indicates differences between two independent sample averages that have random selection conditions, natural distribution, homogeneity and nonexistence of abnormal values in the students' sample. The results are shown in Table 15.

Table 15. The difference between the estimates of students regarding the obstacles of chemistry learning due to gender

\begin{tabular}{|c|c|c|c|c|c|c|}
\hline Dimensions of Obstacles & gender & number & Mean & Std. Deviation & $\mathrm{t}$ & Sig. \\
\hline \multirow{2}{*}{ 1) Obstacles related to chemistry textbooks. } & Male & 36 & 7.39 & 1.644 & \multirow{2}{*}{-0.652} & \multirow{2}{*}{0.516} \\
\hline & Female & 40 & 7.63 & 1.514 & & \\
\hline \multirow{2}{*}{ 2) Obstacles related to students. } & Male & 36 & 10.28 & 1.767 & \multirow{2}{*}{0.008} & \multirow{2}{*}{0.994} \\
\hline & Female & 40 & 10.28 & 1.414 & & \\
\hline \multirow{2}{*}{ 3) Obstacles related to teachers. } & Male & 36 & 8.19 & 2.162 & \multirow{2}{*}{-0.773} & \multirow{2}{*}{0.442} \\
\hline & Female & 40 & 8.58 & 2.123 & & \\
\hline \multirow{2}{*}{ 4) Obstacles related to tools, materials, and structures of laboratories. } & Male & 36 & 2.19 & 0.525 & \multirow{2}{*}{0.365} & \multirow{2}{*}{0.716} \\
\hline & Female & 40 & 2.15 & 0.533 & & \\
\hline All Items & Male & 36 & 35.64 & 5.233 & -0.433 & 0.666 \\
\hline
\end{tabular}


The results in Table 15 indicate apparent differences in averages between the students' estimates regarding obstacles of chemistry learning for ninth grader students due to gender. The probability values of the questionnaire results ranged from (0.642) to (0.994), and for total dimensions was (0.666) which is greater than $(0.05)$ and non-statistically significant, which means there are no statistically significant differences between students' estimates regarding obstacles of chemistry learning for ninth grader students in refugee camps schools due to differences in students gender. The non-statistically significant differences between the responses indicate that students of any gender get education from the same curriculum via similar schools and same the teachers, and live with common environmental conditions in camps.

\subsection{Are There Any Differences between the Estimates of Chemistry Teachers Regarding the Obstacles of Chemistry Learning for Ninth Grader Students Due to Variable Number of Years of Experience?}

Krusal-Wallis test was used to indicate the difference between the estimates of chemistry teachers regarding the obstacles of chemistry learning for ninth grader students due to variable numbers of years of experience. The test analyzed the variance of the differences between three averages and more as an alternative to the ANOFA test when values are nonparametric such as the state of the teacher's questionnaire showed in Table 16.

Table 16. The difference between the estimates of chemistry teachers regarding the obstacles of learning chemistry due to variable number of years of experience

\begin{tabular}{|c|c|c|c|c|c|}
\hline Dimensions of Obstacles & Experience (years) & Number & Mean Rank & $\mathrm{k}^{2}$ & Sig. \\
\hline \multirow{4}{*}{ 1) Obstacles related to chemistry textbooks. } & Less of 5 & 16 & 13.88 & \multirow{4}{*}{0.456} & \multirow{4}{*}{0.929} \\
\hline & $6-10$ & 5 & 13.20 & & \\
\hline & $11-15$ & 2 & 17.50 & & \\
\hline & More than 16 & 4 & 13.75 & & \\
\hline \multirow{4}{*}{ 2) Obstacles related to students. } & Less of 5 & 16 & 14.00 & \multirow{4}{*}{1.495} & \multirow{4}{*}{0.683} \\
\hline & $6-10$ & 5 & 10.90 & & \\
\hline & $11-15$ & 2 & 15.25 & & \\
\hline & More than 16 & 4 & 17.25 & & \\
\hline \multirow{4}{*}{ 3) Obstacles related to teachers. } & Less of 5 & 16 & 13.44 & \multirow{4}{*}{1.085} & \multirow{4}{*}{0.781} \\
\hline & $6-10$ & 5 & 17.20 & & \\
\hline & $11-15$ & 2 & 11.75 & & \\
\hline & More than 16 & 4 & 13.38 & & \\
\hline \multirow{4}{*}{ 4) Obstacles related to schools and education environment. } & Less of 5 & 16 & 13.03 & \multirow{4}{*}{5.111} & \multirow{4}{*}{0.164} \\
\hline & $6-10$ & 5 & 16.10 & & \\
\hline & $11-15$ & 2 & 5.25 & & \\
\hline & More than 16 & 4 & 19.63 & & \\
\hline \multirow{4}{*}{ 5) Obstacles related to tools, materials, and structures of laboratories. } & Less of 5 & 16 & 16.97 & \multirow{4}{*}{6.094} & \multirow{4}{*}{0.107} \\
\hline & $6-10$ & 5 & 10.00 & & \\
\hline & $11-15$ & 2 & 12.75 & & \\
\hline & More than 16 & 4 & 7.75 & & \\
\hline \multirow{4}{*}{ All Items } & Less of 5 & 16 & 14.16 & \multirow{4}{*}{0.043} & \multirow{4}{*}{0.998} \\
\hline & $6-10$ & 5 & 14.10 & & \\
\hline & $11-15$ & 2 & 13.00 & & \\
\hline & More than 16 & 4 & 13.75 & & \\
\hline
\end{tabular}

The results in Table (16) indicated apparent differences in averages between the teachers' estimates regarding obstacles of chemistry learning for ninth grader students due to variable number of years of experience. The probability values of the questionnaire results ranged between (0.107) and (0.929), and for all dimensions was (0.998) which greater than (0.05) and non-statistically significant, which means there are no statistically significant differences between teachers estimates regarding obstacles of chemistry learning for ninth grader students in refugee camps schools due to differences in variable number of years of experience for teachers.

The non-statistical significance can be explained as being due to a variable number of years of experience and to 
obstacles facing teachers. These obstacles are large and most of them are related to school structure, material requirements and displacement. The obstacles are widespread in schools and in the general education system, and the teachers with different years experiences experience the same obstacles. This information was established by the third dimension in the teacher questionnaire. The results agreed with Al-Hartomy's (2014) study in that there are no differences between the teachers' estimates of laboratory use and obstacles of laboratory in chemistry learning due to the variable number of years of experience, also with Al-Muntashri's (2006) study, in that there are no real differences in valuation of using a laboratory and obstacles in biology teaching in secondary schools due to the variable of years of experience.

\subsection{Are There Any Differences Between the Estimates of Chemistry Teachers Regarding the Obstacles of Chemistry Learning for Ninth Grader Students Due to Degree of University Qualification?}

Krusal-Wallis test was used to indicate the difference between the estimates of chemistry teachers regarding the obstacles of chemistry learning for ninth grader students due to level of university qualification, the results showed in Table 17.

Table 17. The difference between the estimates of chemistry teachers regarding the obstacles of chemistry learning due to degree of university qualification

\begin{tabular}{|c|c|c|c|c|c|}
\hline Dimensions of Obstacles & $\begin{array}{c}\text { degree of university } \\
\text { qualification }\end{array}$ & Number & $\begin{array}{l}\text { Mean } \\
\text { Rank }\end{array}$ & $\mathrm{k}^{2}$ & Sig. \\
\hline \multirow{3}{*}{ 1) Obstacles related to chemistry textbooks. } & Institute & 1 & 12.50 & & \\
\hline & University & 24 & 14.17 & 0.098 & 0.952 \\
\hline & Master & 2 & 12.75 & & \\
\hline \multirow{3}{*}{ 2) Obstacles related to students. } & Institute & 1 & 2.00 & & \\
\hline & University & 24 & 14.06 & 3.188 & 0.203 \\
\hline & Master & 2 & 19.25 & & \\
\hline \multirow{3}{*}{ 3) Obstacles related to teachers. } & Institute & 1 & 3.00 & & \\
\hline & University & 24 & 13.96 & 3.083 & 0.214 \\
\hline & Master & 2 & 20.00 & & \\
\hline \multirow{3}{*}{ 4) Obstacles related to schools and education environment. } & Institute & 1 & 9.50 & & \\
\hline & University & 24 & 13.73 & 1.331 & 0.514 \\
\hline & Master & 2 & 19.50 & & \\
\hline \multirow{3}{*}{$\begin{array}{l}\text { 5) Obstacles related to tools, materials, and structures of } \\
\text { laboratories. }\end{array}$} & Institute & 1 & 24.00 & & \\
\hline & University & 24 & 13.25 & 2.331 & 0.312 \\
\hline & Master & 2 & 18.00 & & \\
\hline \multirow{3}{*}{ All Items } & Institute & 1 & 6.00 & & \\
\hline & University & 24 & 13.67 & 3.095 & 0.213 \\
\hline & Master & 2 & 22.00 & & \\
\hline
\end{tabular}

The results in Table 17 indicated to apparent differences in averages between the teachers' estimates regarding obstacles of chemistry learning for ninth grader students to degree of university qualification. The probability values of the questionnaire results ranged between (0.203) to (0.952) and for all dimensions was (0.213) which greater than $(0.05)$ and non-statistically significant, which means there are no statistically significant differences between teachers estimates regarding obstacles of chemistry learning for ninth grader students in refugee camps schools due to degree of university qualification. This explains the non-statistical significance due to teachers' level of university qualification between the dimensions to academic qualification agreeing and has similar training courses. Additionally, ninth grade curriculum is real simple compared to curriculum of secondary school curriculums. It is consistent with Al-Muntashri's (2006) study, in there are no reality differences in valuation of study members of school laboratory using and obstacles in biology teaching in secondary schools that prevent laboratory use due to degree of university qualification.

4.7 Are There Any Differences Between the Estimates of Chemistry Teachers Regarding the Obstacles of Chemistry Learning for Ninth Grader Students Due to Variable Number of Schools in Which Teachers Teach?

Krusal-Wallis test was used to indicate the difference between the estimates of chemistry teachers regarding the obstacles of chemistry learning for ninth grader students due to variable numbers of schools in which teachers teach, the results showed in Table 18. 
Table 18. The difference between the estimates of chemistry teachers regarding the obstacles of learning chemistry due to variable number of schools in which teachers teach

\begin{tabular}{|c|c|c|c|c|c|}
\hline Dimensions of Obstacles & $\begin{array}{l}\text { variable number of schools in which } \\
\text { teachers teach }\end{array}$ & Number & $\begin{array}{l}\text { Mean } \\
\text { Rank } \\
\end{array}$ & $\mathrm{k}^{2}$ & Sig. \\
\hline \multirow{3}{*}{ 1) Obstacles related to chemistry textbooks. } & 1 school & 16 & 12.88 & \multirow{3}{*}{3.850} & \multirow{3}{*}{0.146} \\
\hline & 2 school & 6 & 19.42 & & \\
\hline & More 2 & 5 & 11.10 & & \\
\hline \multirow{3}{*}{ 2) Obstacles related to students. } & 1 school & 16 & 13.47 & \multirow{3}{*}{0.364} & \multirow{3}{*}{0.834} \\
\hline & 2 school & 6 & 13.83 & & \\
\hline & More 2 & 5 & 15.90 & & \\
\hline \multirow{3}{*}{ 3) Obstacles related to teachers. } & 1 school & 16 & 12.38 & \multirow{3}{*}{3.006} & \multirow{3}{*}{0.222} \\
\hline & 2 school & 6 & 13.83 & & \\
\hline & More 2 & 5 & 19.40 & & \\
\hline \multirow{3}{*}{$\begin{array}{l}\text { 4) Obstacles related to schools and education } \\
\text { environment. }\end{array}$} & 1 school & 16 & 10.13 & \multirow{3}{*}{9.534} & \multirow{3}{*}{0.009} \\
\hline & 2 school & 6 & 19.33 & & \\
\hline & More 2 & 5 & 20.00 & & \\
\hline \multirow{3}{*}{$\begin{array}{l}\text { 5) Obstacles related to tools, materials, and structures } \\
\text { of laboratories. }\end{array}$} & 1 school & 16 & 15.94 & \multirow{3}{*}{3.266} & \multirow{3}{*}{0.195} \\
\hline & 2 school & 6 & 13.25 & & \\
\hline & More 2 & 5 & 8.70 & & \\
\hline \multirow{3}{*}{ All Items } & 1 school & 16 & 12.16 & \multirow{3}{*}{2.124} & \multirow{3}{*}{0.346} \\
\hline & 2 school & 6 & 16.58 & & \\
\hline & More 2 & 5 & 16.80 & & \\
\hline
\end{tabular}

The results in Table 18 indicated apparent differences in averages between the teachers' estimates regarding obstacles of chemistry learning for ninth grader students to degree of university qualification. The probability values of the questionnaire results ranged between $(0.009)$ to $(0.438)$ and for all dimensions was $(0.346)$. The fourth dimension showed smaller than (0.01) and the value of $\mathrm{K}^{2}$ was (9.534) and had a statistically significant, other dimensions and total dimensions of the questionnaire gave probability values of $\mathrm{K}^{2}$ greater than $(0.05)$ and were non-statistically significant, which means there are no statistically significant differences between teachers estimates regarding obstacles of chemistry learning for ninth grader students in refugee camps schools due to variable numbers of schools in which teachers teach. The fourth dimension explains that teachers who teach in more than one school have different answers than those who teach in one school only. These teachers with fewer teaching contexts have less awareness of the reality of teaching in difficult environments and less knowledge of the obstacles that students and teachers face.

4.8 What Is the Suggested Approach to Overcoming Obstacles of Learning Chemistry for Ninth Grader Students in the Syrian Arab Republic-Idlib Suburb Refugee Camps as Perceived by Teachers and Students?

\subsubsection{Lack of Laboratories and Tools for Experiments}

This obstacle is the largest and most widespread among the obstacles faced by students of ninth grade in the refugee camps of rural Idlib North, which was confirmed by teachers and students in their answers. To overcome it, there are two solutions (stable and temporary):

1) A complete study should be prepared according to official and trustworthy regulations to offer laboratories equipped with all that is necessary to do experiments such as equipment, tools and supplies. In addition, safety and laboratory expenses must be dealt with. These requirements then should be submitted to the Education Directorate to take necessary steps. Organizations supporting of local education in camps, and international organizations for education support Such as UNICEF should also be contacted.

2) Whatever temporary laboratory that is available should be used to do experiments and break the fear obstacle that students face regarding doing experiments or working with tools and chemical materials.

3) Available alternatives should be used to do experiments. Emphasis should be placed on teachers doing experiments before classes to ensure the suitability of alternatives and the success of experiments in accordance with safety and the allocated time.

4) Moral and material incentives should be provided for teachers commensurate with the time and effort spent in 
laboratory work.

5) Videos of experiments performed by specialist teachers should be provided and shown to students when they cannot do them in the laboratory.

6) Educational trips for students to factories and nearby chemical laboratories should be organized to review the industrial process and to provide adequate explanations by the teacher and experts working according to the level of knowledge of students.

\subsubsection{Lack of Use of the Chemical Concepts in Textbook in Students' Lives}

1) A special curriculum should be prepared for students in refugee camps that is related to their lives and that touches on their problems such as ideas and examples that find a way to improve their situation, In this way, students feel that chemistry can develop their abilities to solve problems and find better solutions (Such as water packing, pollution and how to filter it - heating substances on coal and resulting gases - solar energy and mechanism of production and storage in lead batteries - techniques of energy production and possible alternatives - methods of waste treatments - methods to deal with remnants of war - methods of protection from toxic gases ...).

2) New units and chapters should be added to current curriculum related to concepts in students' reality which can provide solutions to many problems in the refugee camps and raise awareness of how chemistry could help.

3) New examples of the chemical concepts should be added to curriculum related to students' reality.

4) Some problems related to chemistry that face students in refugee camps can be solved in scientific steps.

4.8.3 Students Save the Information without Understanding

This obstacle is due to teachers using indoctrination method rather than education methods in classes. In order to overcome this, the teacher should vary the educational tools used in classes, as well as follow different teaching methods that fit with chemistry teaching because using just one method makes students idle, loses their focus, while variation in methods make students attentive to the teacher. It should be noted that unselective transfer of teaching methods and the improper use of educational methods in classes distracts student and makes them unable to follow the teacher so it is necessary that teachers develop a plan prepared with clear proposals of teaching methods.

4.8.4 Some Students Have a Long Time Out of School and Are Automatically Upgraded to a Class That Is Not Appropriate for Their Level

The displacement movements because of war in Syria caused large numbers of students out of schools in camps. In order to understand basic information from past classes so it is possible to match the scientific level of their students peers in the same class, the educational organization in the refugee camps should undertake corrective course in basics chemistry for students who have been out of school for extended periods and students who have low success with chemistry. These courses can be established in a variety of formats:

1) Classes out of schools' times.

2) Courses in summer and holidays.

3) A special team of teachers and programmers design interactive educational programs that can be accessed on computers or smart phones. These programs contain several interactive learning modules and would be available any time.

\subsubsection{Lack of Communication Between School and Family}

The displacement of students can result in weaker links between school and students' family, which can be overcome in several ways:

1) Making Parents' Meetings to discuss ways of communication and to enhance cooperation between parents and teachers in following-up on students' progress.

2) Sending periodic reports to students' families using available social media to communicate status and tests grades.

3) Creating a website for each school so that families can see tests grades and follow students, and also submit their proposals and reviews. 


\section{Recommendations}

The authors recommend study obstacles of chemistry learning in secondary schools, and they suggest that schools design interactive programs for chemistry learning and measure its impact at ninth grade students. A necessary study of experiments affects students' development of skills and enhancement of creative thinking. In addition, the effect of accelerated education courses of chemistry learning on ninth grade students in refugee camps should be studied, and chemistry curriculums specific to students in refugee camps should be developed.

\section{Conclusions}

There are many obstacles facing teachers and ninth grade students in refugee camps of Syria. In order, these are: obstacles related to tools, materials, and structures of laboratories as the most significant, then obstacles related to students, teachers, schools and education environment, and chemistry textbooks. There are no statistically significant differences at the level $(0.05)$ between the estimates of chemistry teachers or students regarding the obstacles of learning chemistry for ninth grader students due to gender or experience or degree of university qualification or variable number of schools in which teachers teach except the obstacles related to schools and education environment have a statistically significant difference at the level $(0.01)$ due to variable number of schools in which teachers teach.

\section{Acknowledgements}

Grateful thanks for Mrs. Rosemary Whitehead from Sheffield University for language reviews of the article, and greatly appreciate for Suriyeli Iş Admları Derneği (SIAD) Organization for financial support for this work.

\section{References}

Abo-Jlala, S. (2005). The new in sciences teaching experiments in light of modern strategies. Al-falah library, United Arab Emirates.

Admas, A., \& Adane, L. (2011). Relevance and safety of Chemistry laboratory experiments from students perspective: A case study at Jimma University. Educational Research, 2(12), 1749-1758.

Al-Dofairy, M., \& Habib, S. (2012). Modern teaching methods in modern curriculum. Kuwait.

Al-Hammadi, T. (2007). The extent of the implementation of practical chemistry experiments for secondary school in the capital Sana'a schools (Unpublished master's thesis). Sana'a University, Yemen.

Al-Hartomy, A. (2014). The reality of use of the laboratory and the obstacles of using it in teaching chemistry courses from the perspectives of relationship of teacher and laboratory course in Leith Education Province for boys (Master's thesis, Umm Al-Qura University, Saudi Arabia). Retrieved from http://libback.uqu.edu.sa/hipres/futxt/16579.pdf

Al-Khalili, Y. (1988). The level of attention to use of the laboratory in science teaching and the obstacles in public secondary schools in Jordan as perceived by teachers. The Educational Journal, Kuwait University, 4(15), 343-363.

Al-Muntashri, A. A. (2006). The reality of use of laboratory in biology teaching to secondary stage in Al-Qunfudah province as perceived by teachers, education supervisors and laboratory technicians (Unpublished Master's thesis). Umm Al-Qura University, Saudi Arabia.

Al-Rasheed, A. (2003). Study of science education in the primary and intermediate stages for students in the kingdom of Saudi Arabia. King Abdul-Aziz city for science and technology, Saudi Arabia. Retrieved from https://faculty.psau.edu.sa/h.algomaizy/article/al0000000461

Al-Rifai, A. (2006). The extent of teachers using of laboratories to chemistry teaching for secondary schools in Sana' city. Journal of Education Studies, 12(21). Retrieved from http://libback.uqu.edu.sa/hipres/futxt/16579.pdf

Al-Saady, A. A., \& Ouda, T. (2006). Introduction to science teaching. Dar Al-Kitab Al-Hadith, Egypt. Retrieved from https://www.neelwafurat.com/itempage.aspx?id=egb153917-5164822\&search=books

Al-Suwian, K. N. (2006). The reality of the secondary chemistry labs in Riyadh city and its needs of education techniques (Unpublished master's thesis). King Saud University, Saudi Arabia.

At-Allah, M. (2001). Methods of sciences teaching. Dar Al-Massira for Publishing, Jordan.

Basul, A. (1987). Obstacles to learning and teaching chemistry for the second and third secondary grades in the scientific branch as perceived by teachers (Unpublished master's thesis). Yarmouk University, Jordan.

BouJaoude, S. (2006). A profile of pre-college chemistry teaching in Beirut. Eurasia Journal of Mathematics. 
Science and Technology Education, 2(3), 124-143. https://doi.org/10.12973/ejmste/75470

Feyzioglu, B., Demirdag, B., Ates, A., Cobanoglu, I., \& Altun, E. (2011). Chemistry Teachers Perceptions on Laboratory Applications: Izmir Sample. Educational Sciences: Theory \& Practice, 11(2), 1024-1029.

Hindi, H. (2008). The extent of chemistry understanding of third grade scientific secondary students in Riyadh city (Master's thesis, King Saud University, Saudi Arabia). Retrieved from https://ecsme.ksu.edu.sa/sites/ecsme.ksu.edu.sa/files/imce_images/1009.pdf

Jegde, S. (2007). Student's anxiety towards the learning of Chemistry in some Nigerian secondary schools. Educational Research and Review, 2(7), 193-197. Retrieved from https://eric.ed.gov/?id=EJ900195

Mahmoud, M. (2010). The difficulties faced by biological science teachers in using the laboratory. Journal of Diyala, 45, 432-447. Retrieved from https://www.iasj.net/iasj?func=fulltext\&aId=17868

Mahmoud, S.-A. (2012). Chemistry document for secondary stage, Center of curriculums education materials development. Egypt. Retrieved from http://moe.gov.eg/ccimd/pdf/doc-chemistry_quality2.pdf

Taha, H. (2008). The practical applications handicaps in teaching chemistry at the intermediate stage as perceived by teachers. Journal of Al-qadisiya in Arts and Education Science, 7(1-2), 131-333. Retrieved from http://libback.uqu.edu.sa/hipres/futxt/16579.pdf

Zayton, A. (2008), Methods of Teaching Science. Dar-Al Shorok, Jordan. Retrieved from https://ia800202.us.archive.org/7/items/kadaabidi_yahoo_20160326/\%D8\%B7\%D8\%B1\%D8\%A7\%D8\%A 6\%D9\%82\%20\%D8\%AA\%D8\%AF\%D8\%B1\%D9\%8A\%D8\%B3\%20\%D8\%A7\%D9\%84\%D8\%B9\%D9 \%84\%D9\%88\%D9\%85\%20\%D9\%84\%D8\%B9\%D8\%A7\%D9\%8A\%D8\%B4\%20\%D8\%B2\%D9\%8A\%D $8 \%$ AA\%D9\%88\%D9\%86\%20.pdf

\section{Copyrights}

Copyright for this article is retained by the author(s), with first publication rights granted to the journal.

This is an open-access article distributed under the terms and conditions of the Creative Commons Attribution license (http://creativecommons.org/licenses/by/4.0/). 